\title{
Strength and torsion fracture mechanism of commercially pure titanium with ultrafine-grained structure
}

\author{
G. V. Klevtsov ${ }^{\dagger, 1}$, R.Z. Valiev², N.A. Klevtsova ${ }^{1}$, M. V. Fesenyuk³ \\ M.N. Tyurkov' ${ }^{1}$ A. V. Polyakov² \\ ${ }^{\dagger}$ Klevtsov11948@mail.ru \\ ${ }^{1}$ Togliatti State University, Togliatti, 445020, Russia \\ ${ }^{2}$ Research Institute of Physics of Advanced Materials, USATU, Ufa, 450008, Russia \\ ${ }^{3}$ JSC "PA Strela", Orenburg, 460005, Russia
}

\begin{abstract}
The mechanical behavior and the mechanism of torsional fracture of medical grade titanium Grade4 with an ultrafinegrained (UFG) structure in comparison with a coarse-grained (CG) structure were investigated. CG titanium $\left(d_{\mathrm{av}}=25 \mu \mathrm{m}\right)$ was investigated in the hot-rolled state. To obtain the UFG structure, two processing regimes were used. In the first regime, homogenization annealing was carried out at a temperature of $680^{\circ} \mathrm{C}$ for 1 hour, then equal-channel angular pressing ( 6 passes) according to the "Conform" scheme (ECAP-C) at a workpiece and tool temperature of $250^{\circ} \mathrm{C}$ (route Bc, $\varphi=120^{\circ}$ ). The average grain size is equal to $0.4 \mu \mathrm{m}$. In the second regime, after homogenization annealing and six ECAP-C passes, the workpieces were drawn at a temperature of $200^{\circ} \mathrm{C}(\mathrm{ECAP}-\mathrm{C}+\mathrm{D})$. The average grain size is equal to $0.2 \mu \mathrm{m}$. The torsion test of samples with a diameter of $3 \mathrm{~mm}$ (close to the diameter of screws for fixing plates in traumatology) was carried out on a KTS 403-20-0.5 installation in accordance with GOST 3565-80. The torque, number of revolutions and angle of twisting of the samples made from CG and UFG titanium, as well as the mechanical properties of titanium during torsion were evaluated. Torsion tests have shown that the torsional strength and the torsional yield strength of UFG titanium increase, and the relative shear decreases in comparison with similar properties of CG titanium. In addition, the mode of nanostructuring (ECAP-C+D) provides higher values of the torsional strength properties of titanium compared to ECAP-C, which is favorable from the standpoint of resistance to fracture of titanium screws by torsion. On the surface of the fractures, there are three regions differing in microrelief: the central part of the fracture, the middle (transitional) and the peripheral parts. In the central part of the fractures, the microrelief consists of equiaxed dimples and structureless areas. In the middle part, shear dimples dominate, and in the peripheral part of fractures, areas of shear dimples alternate with areas of the rubbed surface.
\end{abstract}

Keywords: titanium, ultrafine-grained (UFG) structure, equal channel angular pressing (ECAP), torsion test, fracture, torque, microrelief.

УДК: 620.17

\section{Прочность и механизм разрушения при кручении технически чистого титана с ультрамелкозернистой структурой}

\author{
Клевцов Г. В. ${ }^{\dagger, 1}$, Валиев Р. 3. ${ }^{2}$, Клевцова Н. А. ${ }^{1}$, Фесенюк М. В. ${ }^{3}$, \\ Тюрьков М.Н. ${ }^{1}$, Поляков А. В. ${ }^{2}$ \\ ${ }^{1}$ Тольяттинский государственный университет, Тольятти, 445020, Россия \\ ${ }^{2}$ НИИ физики перспективных материалов УГАТУ, Уфа, 450008, Россия \\ ${ }^{3} \mathrm{AO}$ «ПО «Стрела», Оренбург, 460005, Россия
}

Исследовали механическое поведение и механизм разрушения при кручении медицинского титана марки Grade4 с ультрамелкозернистой (УМЗ) структурой в сравнении с крупнозернистой (КЗ) структурой. К3 титан $(d$ ср. $=25$ мкм) исследовали в горячекатаном состоянии. Для получения УМЗ структуры использовали два режима обработки. По первому режиму проводили гомогенизационный отжиг при температуре $680^{\circ} \mathrm{C}, 1$ час, затем равноканальное угловое прессование (6 проходов) по схеме «Конформ» (РКУП-К) при температуре заготовки и оснастки $250^{\circ} \mathrm{C}$ 
(маршрут Bc, $\varphi=120^{\circ}$ ). Средний размер зерна 0.4 мкм По второму режиму после гомогенизационного отжига и шести проходов РКУП-К заготовки подвергали волочению при температуре $200^{\circ} \mathrm{C}($ РКУП-К+В). Средний размер зерна 0.2 мкм. Испытание на кручение образцов диаметром 3 мм (близких к диаметру шурупов для крепления пластин в травматологии) проводили на установке КТС 403-20-0.5 согласно ГОСТ 3565-80. Оценивали крутящий момент, количество оборотов и угол закручивания образцов из КЗ и УМЗ титана, а также механические свойства титана при кручении. Результаты исследования показали, что пределы прочности и текучести при испытании на кручение УМЗ титана возрастают, а относительный сдвиг снижается по сравнению с аналогичными свойствами КЗ титана. Кроме того, режим наноструктурирования (РКУП-К+В) обеспечивает более высокие значения прочностных свойств титана при испытании на кручение по сравнению с РКУП-К, что благоприятно с позиции сопротивления разрушению титановых винтов путем скручивания. На поверхности изломов наблюдаются три области, отличающиеся микрорельефом: центральная часть излома, средняя (переходная) и периферийная часть. В центральной части изломов микрорельеф состоит из равноосных ямок и бесструктурных участков. В средней части доминируют ямки сдвига, а в периферийной части изломов участки с ямками сдвига чередуются с участками затертой поверхности.

Ключевые слова: титан, ультрамелкозернистая (УМЗ) структура, равноканальное угловое прессование (РКУП), испытание на кручение, излом, крутящий момент, микрорельеф.

\section{1. Введение}

Широкое использование «щадящих» операционных технологий в челюстно-лицевой хирургии, стоматологии, травматологии и других областях медицины, позволяющих минимизировать травмирование во время операции и сократить срок послеоперационной реабилитации, невозможно без миниатюризации медицинских изделий, главным образом, пластин для остеосинтеза костей и шурупов для крепления пластин. В свою очередь решение задачи миниатюризации изделий базируется на разработке нового класса высокопрочных биосовместимых материалов [1-3]. Этим требованиям в полной мере отвечают металлические материалы с ультрамелкозернистой (УМЗ) структурой, полученные методами интенсивной пластической деформации (ИПД) [4-6]. Многочисленные исследования последних двух десятилетий убедительно свидетельствуют, что создание УМЗ структур позволяет значительно увеличить твердость, прочность и усталостную долговечность металлических материалов [7-10]. Это относится, прежде всего, к широко используемому в медицине титану и его сплавам [1,6,10-15]. Технически чистый титан марки Grade4 является одним из лучших металлических материалов для медицинских имплантатов длительного использования. В зависимости от конструкции изделия, продолжительности его нахождения в организме человека и условий эксплуатации материал медицинских имплантатов, наряду с биосовместимостью, должен обладать высокой конструкционной прочностью (трещиностойкостью, ударной вязкостью, сопротивляемостью усталостному разрушению, скручиванию). Статистический анализ эксплуатационных повреждений медицинских изделий показал [16-19], что большой процент разрушения титановых шурупов для крепления пластин в травматологии и челюстнолицевой хирургии происходит путем скручивания в гладкой области шурупа между резьбовой частью и головкой в процессе откручивания сросшихся с костью шурупов после выздоровления пациента или по другим причинам [19]. Влияние УМЗ состояния материала на сопротивление винтов разрушению такого рода в литературе практически не рассматривается. Поэтому исследование влияния УМЗ структуры на сопротивление материала разрушению при кручении является актуальной задачей.

Целью настоящей работы является оценка прочности и механизма разрушения при кручении медицинского УМЗ титана по сравнению с крупнозернистым (КЗ) титаном.

\section{2. Материал и методики исследования}

В качестве исследуемого материала в КЗ и УМЗ состояниях был выбран широко применяемый в медицине титан Grade4. Образцы титана в К3 состоянии представлял собой горячекатаные прутки со средним размером зерна 25 мкм. УМЗ состояние металла было получено по двум режимам. Первый режим включал в себя: предварительную термообработку в виде гомогенизационного отжига при температуpe $680^{\circ} \mathrm{C}, 1$ час + шесть проходов равноканального углового прессования по схеме «Конформ» (РКУП-К) при температуре заготовки и оснастки $250^{\circ} \mathrm{C}$ (маршрут Bc, $\varphi=120^{\circ}$ ) [4,6]. Сечение полученных заготовок составляло $11 \times 11$ мм. По второму режиму, после гомогенизационного отжига и шестью проходов РКУП-К, заготовки подвергали волочению при температуре $200^{\circ} \mathrm{C}$ (РКУП-К+В). По данному режиму были получены заготовки в виде прутков диаметром 5 мм.

Тонкую структуру УМЗ титана исследовали в просвечивающем электронном микроскопе (ПЭМ) JEM-2100. Испытание титана на твердость проводили на твердомере ТН 300; испытание на растяжение образцов диаметром 3 мм - на универсальной испытательной машине Н50КТ. Испытанию на кручение подвергали цилиндрические образцы диаметром рабочей части 3 мм (близким к диаметру шурупов для крепления пластин в травматологии) из К3 и УМЗ титана на установке КТС 403-20-0.5 согласно ГОСТ $3565-80$ с учетом 
ГОСТ Р 50581-93 (ИСО 6475-89). По диаграмме «крутящий момент - угол закручивания» рассчитывали механические свойства титана при кручении [20]. Исследование микрорельефа изломов проводили в растровом электронном микроскопе (PЭМ) JEOL JCM-6000.

\section{3. Результаты исследования и их обсуждение}

Тонкая структура титана Grade4 после РКУП-К и РКУП-К+В (Рис. 1) характеризуется измельчением зерна и значительным повышением плотности дефектов кристаллической структуры по сравнению с КЗ состоянием. Средний размер зерна и механические свойства титана после различных видов обработки представлены в Табл. 1.

Анализ диаграмм «крутящий момент - угол закручивания» показал, что при испытании образцов на кручение из КЗ и РКУП-К+В титана угол закручивания монотонно возрастает с увеличением крутящего момента, что является характерным для большинства материалов (Рис. 2, кривые 1, 3) [20]. В случае РКУП-К имеет место увеличение угла закручивания практически при постоянном значении крутящего момента (Рис. 2, кривая 2). Можно предположить, что такой характер кривой обусловлен наличием ячеистой дислокационной структуры, образующейся в процессе РКУП-К (Рис. 1а). Титан имеет высокую энергию дефектов упаковки, что затрудняет расщепление дислокаций и облегчает поперечное скольжение. При этом область около источников остается практически свободной от дислокаций, что позволяет вновь образующимся дислокациям свободно скользить внутри ячеек, обеспечивая деформацию практически без увеличения нагрузки. Последующее

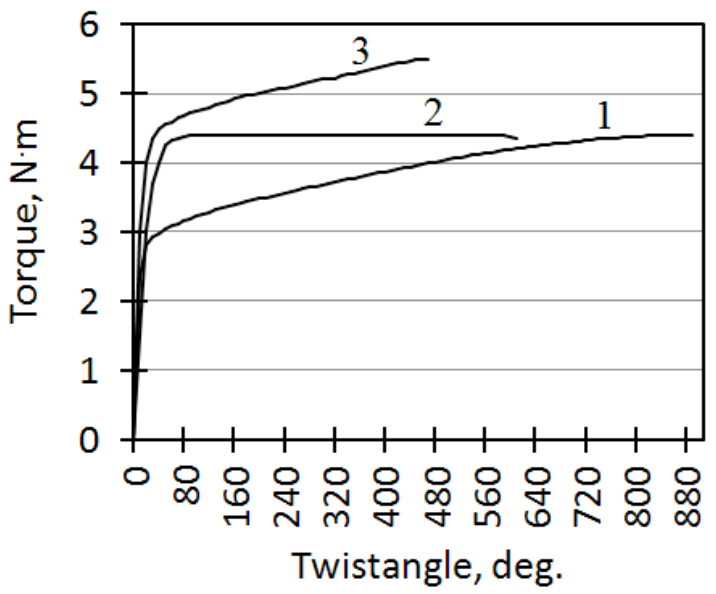

Рис. 2. Диаграммы «крутящий момент - угол закручивания» при испытании на кручение образцов из КЗ (1) и УМЗ титана: (РКУП-К) (2) и (РКУП-К+В) (3).

Fig. 2. Diagrams "torque - twist angle" during torsion testing of samples with CG (1) and UFG titanium: (ECAP-C) (2) and (ECAP-C+D) (3).

после РКУП-К волочение значительно увеличивает плотность дефектов кристаллического строения и создает текстуру деформации титана, что затрудняет легкое скольжение дислокаций в процессе деформации.

Расчет среднего значения предела прочности $\left(\tau_{\mathrm{k}}\right)$, предела текучести $\left(\tau_{0.3}\right)$ и относительного сдвига $(g)$ титана при кручении показал (Табл. 2), что прочностные характеристики УМЗ титана возрастают, а относительный сдвиг снижется по сравнению с КЗ титаном. Наиболее высокие значения прочностных свойств титана имеют место после обработки РКУП-К+В (Табл. 2), что является благоприятным фактором, снижающим вероятность

Табл. 1. Средний размер зерна и механические свойства титана Grade4 при растяжении.

Table 1. Average Grain size and tensile properties of titanium Grade4.

\begin{tabular}{|c|c|c|c|c|c|}
\hline $\begin{array}{c}\text { Состояние } \\
\text { Condition } \\
\end{array}$ & $\begin{array}{c}d_{\text {cp. }}, \text { мКм } \\
d_{\text {av. }}, \mu \mathrm{m}\end{array}$ & $\begin{array}{l}\mathrm{HB} \\
\mathrm{HB}\end{array}$ & $\begin{array}{l}\sigma_{\mathrm{B}}, \mathrm{M \Pi a} \\
\sigma_{\mathrm{w}}, \mathrm{MPa}\end{array}$ & $\begin{array}{l}\sigma_{0.2}, \mathrm{M \Pi а} \\
\sigma_{0.2}, \mathrm{MPa}\end{array}$ & $\begin{array}{l}\delta, \% \\
\delta, \%\end{array}$ \\
\hline $\begin{array}{c}\text { К3 (горячекатаное) } \\
\text { CG (hot rolled) }\end{array}$ & 25 & 238 & $710 \pm 15$ & $565 \pm 11$ & $20 \pm 0.5$ \\
\hline $\begin{array}{l}\text { УМЗ (РКУП-К) } \\
\text { UFG (ЕСАР-С) }\end{array}$ & 0.4 & 249 & $1050 \pm 15$ & $900 \pm 25$ & $14 \pm 0.7$ \\
\hline $\begin{array}{l}\text { УМЗ (РКУП-К+В) } \\
\text { UFG (ЕСАР-С+D) }\end{array}$ & 0.2 & 281 & $1250 \pm 10$ & $1100 \pm 30$ & $11 \pm 0.5$ \\
\hline
\end{tabular}

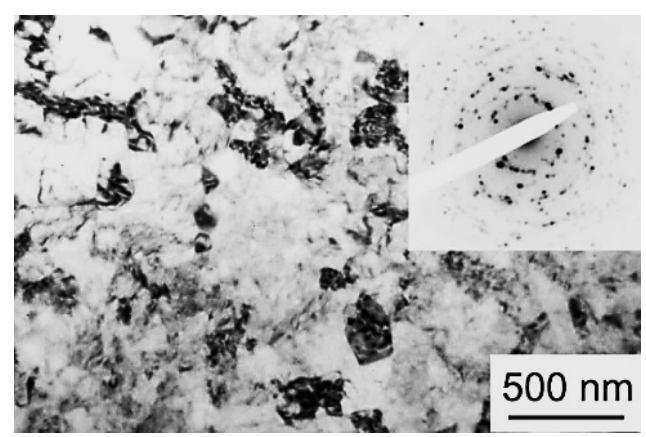

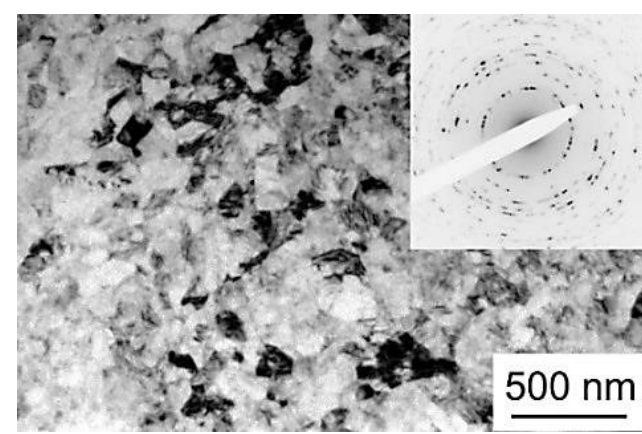

$\mathrm{b}$

Рис. 1. Тонкая структура титана Grade4 после РКУП-К (а) и РКУП-К+В (b) (ПЭМ).

Fig. 1. Fine structure of titanium Grade4 after ECAP-C (a) and ECAP-C+D (b) (TEM). 
разрушения при откручивании сросшихся с костью шурупов при остеосинтезе костей.

Рассмотрим макро- и микростроение изломов, полученных при кручении, на примере образцов из КЗ и УМЗ титана после РКУП-К+В. Из Рис. 3 видно, что разрушение образцов как КЗ, так и УМЗ титана произошло по механизму среза. На поверхности всех полученных изломов, независимо от состояния титана, можно выделить три области (Рис. 3): центральную часть, отличающуюся большой шероховатостью, переходную (среднюю) часть и относительно гладкую периферийную часть. В центральной части изломов микрорельеф состоит из равноосных ямок отрыва и бесструктурных участков (Рис. $4 \mathrm{a}, \mathrm{d}$ ), образованных, по-видимому, от контакта ответных поверхностей излома. В средней части изломов доминируют ямки сдвига (Рис. $4 \mathrm{~b}, \mathrm{e}$ ); встречаются учас-

Табл. 2. Механические свойства титана Grade4 при кручении.

Table 2. Torsional mechanical properties of titanium Grade4.

\begin{tabular}{|c|c|c|c|c|c|c|}
\hline $\begin{array}{c}\text { Состояние } \\
\text { State }\end{array}$ & $\begin{array}{c}\text { Крутящий момент, } \mathrm{H} \cdot \mathrm{M} \\
\text { Twisting moment, N·m }\end{array}$ & $\begin{array}{c}\text { Обороты, } n \\
\text { Revs, } n\end{array}$ & $\begin{array}{c}\text { Угол закручивания, гр. } \\
\text { Angle twisting, deg. }\end{array}$ & $\begin{array}{c}\tau_{\mathrm{k}}, \mathrm{MПа} \\
\tau_{\mathrm{k}}, \mathrm{MPa}\end{array}$ & $\begin{array}{c}\tau_{0.3}, \mathrm{MПа} \\
\tau_{0.3}, \mathrm{MPa}\end{array}$ & $\begin{array}{c}g, \% \\
g, \%\end{array}$ \\
\hline $\begin{array}{c}\text { К3 (горячекатаное) } \\
\text { СG (hot rolled) }\end{array}$ & $4.51 \pm 0.35$ & $2.43 \pm 0.07$ & $875^{\circ} 24^{\prime} \pm 250$ & $920 \pm 37$ & $641 \pm 46$ & $154 \pm 3.5$ \\
\hline $\begin{array}{c}\text { УМ3 (РКУП-К) } \\
\text { UFG (ЕСАР-С) }\end{array}$ & $4.78 \pm 0.23$ & $1.45 \pm 0.92$ & $520^{\circ} 30^{\prime} \pm 330$ & $944 \pm 28$ & $769 \pm 31$ & $92 \pm 5.4$ \\
\hline $\begin{array}{l}\text { УМ3 (РКУП-К+В) } \\
\text { UFG (ЕСАР-С+D) }\end{array}$ & $5.48 \pm 0.15$ & $1.39 \pm 0.06$ & $498^{\circ} 40^{\prime} \pm 220$ & $1014 \pm 24$ & $831 \pm 18$ & $87 \pm 2.0$ \\
\hline
\end{tabular}

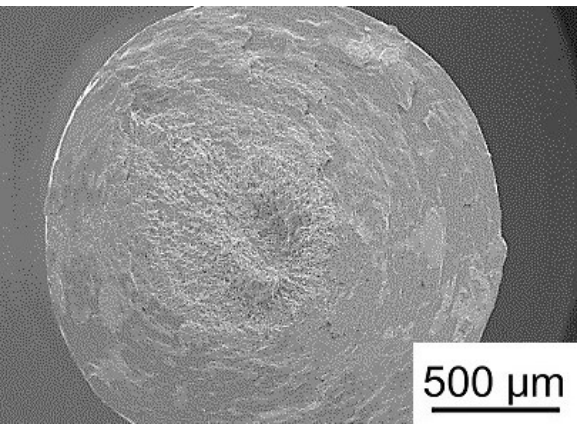

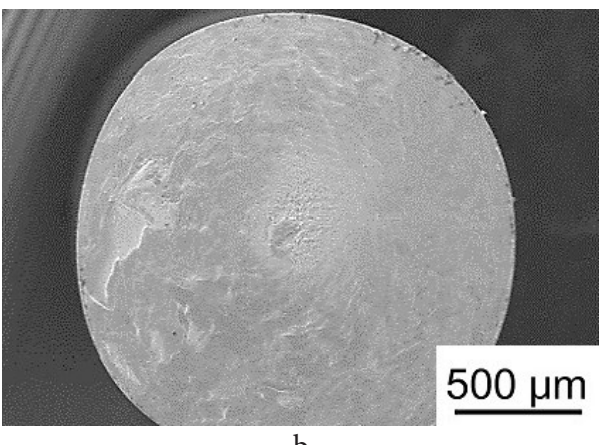

b

Pис. 3. Общий вид изломов образцов на кручение из КЗ (а) и УМЗ (РКУП-К+В) титана (b) (РЭМ).

Fig. 3. General view of torsional fractures of specimens from CG (a) and UFG (ECAP-C+D) titanium (b) (SEM).

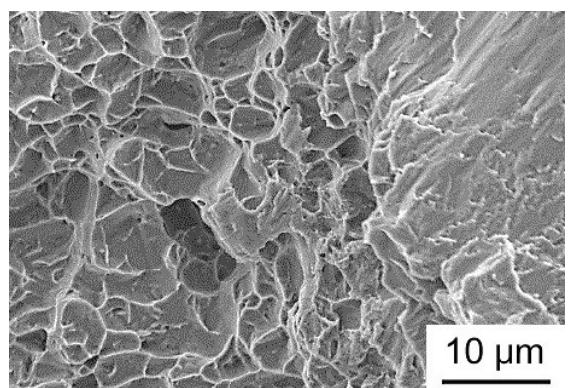

a

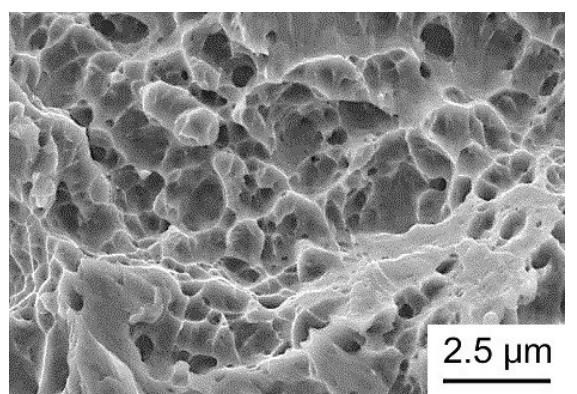

$\mathrm{d}$

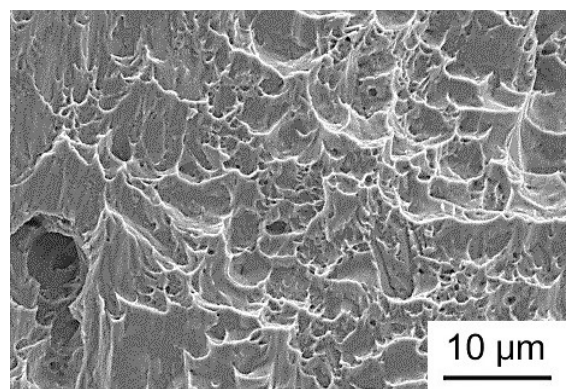

$\mathrm{b}$

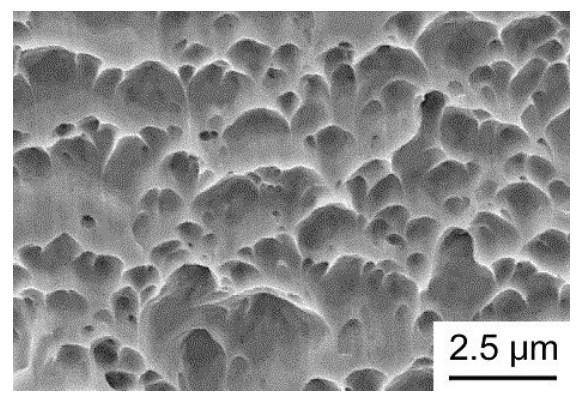

e

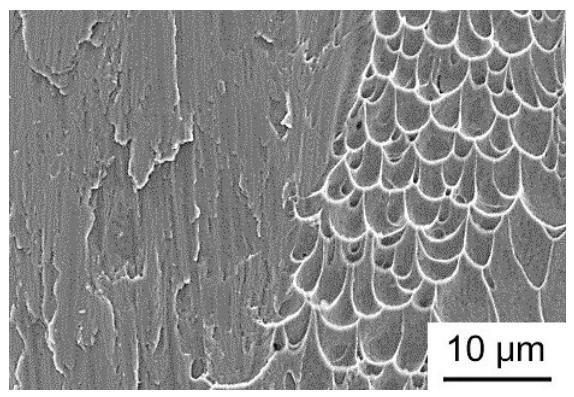

c

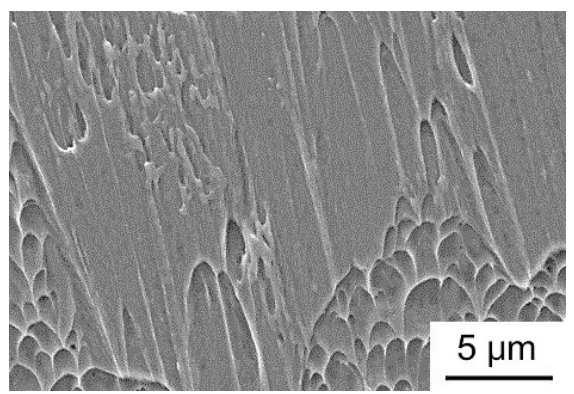

$\mathrm{f}$

Рис. 4. Микрорельеф изломов образцов КЗ (а-c) и УМЗ (РКУП-К+В) (d-f) титана, испытанных на кручение. Микрорельеф центральной $(\mathrm{a}, \mathrm{d})$, средней $(\mathrm{b}, \mathrm{e})$ и периферийной $(\mathrm{c}, \mathrm{f})$ областей изломов. (a-c) $-\times 1000 ;(\mathrm{f})-\times 2000 ;(\mathrm{d}, \mathrm{e})-\times 4000(\mathrm{PEM})$.

Fig. 4. Microrelief of fractures of samples CG (a-c) and UFG (ECAP-C+D) (d-f) titanium, tested for torsion. Microrelief of the central (a, d), middle (b, e) and peripheral (c, f) fracture regions. (a-c) $-\times 1000$; (f) $-\times 2000$; $(d, e)-\times 4000$ (SEM). 
тки с затертой поверхностью. В периферийной части изломов отдельные участки с неглубокими ямками сдвига чередуются с большими по площади участками затертой поверхности (Рис. $4 \mathrm{c}, \mathrm{f}$ ). Обращает на себя внимание тот факт, что при разрушении образцов КЗ титана во всех участках изломов образуются более глубокие ямки по сравнению с разрушением УМЗ титана, что, безусловно, связано с более высокой пластичностью КЗ титана.

Можно предположить, что разрушение при кручении начинается с периферийной области, где образуются ямки сдвига. При дальнейшем кручении ямки сдвига в периферийной области становятся полностью или частично затертыми из-за контакта с ответными поверхностями изломов. В средней части изломов этот эффект проявляется не так явно, а в центральной части изломов доминируют нормальные напряжения, возникающие на конечной стадии разрушения, о чем свидетельствуют преимущественно равноосные ямки.

\section{4. Выводы}

1. Предел прочности и предел текучести УМЗ титана Grade4 при кручении возрастают, а значение относительного сдвига снижается по сравнению с КЗ титаном, что является благоприятным фактором, уменьшающим вероятность разрушения при откручивании сросшихся с костью шурупов при остеосинтезе костей. Следовательно, УМ3 титан Grade4 является более перспективным материалом для изготовления медицинских шурупов, по сравнению с КЗ титаном.

2. Режим наноструктурирования РКУП по схеме «Конформ» с последующей вытяжкой (РКУП-К+В) обеспечивает более высокие значения прочностных свойств титана Grade4 при кручении и более низкие значения относительного сдвига по сравнению с РКУП-К, что является благоприятным фактором с позиции сопротивления скручиванию медицинских шурупов.

3. На поверхности всех изломов образцов наблюдаются три области, отличающиеся микрорельефом поверхности и отражающие процесс разрушения образцов при кручении. Разрушение начинается с образования ямок сдвига в средней и периферийной области, которые при дальнейшем вращении образца частично или полностью затираются. Окончательное разрушение происходит под действием нормальных напряжений в центральной части образца.

Благодарности/Acknowledgements. Работа выполнена при финансовой поддержке РНФ (междисииплинарные проекты: 20-69-47059 и частично 20-63-47027). Авторы благодарят сотрудников НИИ ФПМ УГАТУ Г. Рааба и Р. Мустабина за помощь в проведении экспериментальной части работы. / This work was financially supported by the Russian Science Foundation (interdisciplinary projects: 20-69-47059 and partially 20-63-47027). The authors thank the Researchers G. Raab and R. Mustafin of the SRI Physics of Advanced Materials USATU for the help in carrying out the experimental part of the work.

\section{Литература/References}

1. I.P. Semenova, G.V. Klevtsov, N.A. Klevtsova, G.S. Dyakonov, A.A. Matchin, R.Z. Valiev. Advanced Engineering Materialsю. 18 (7), 1216 (2016). Crossref

2. A. V. Popkov. The Genius of Orthopedics. 3, 94 (2014). (in Russian) [А. В. Попков. Гений Ортопедии. 3, 94 (2014).]

3. T. Fujishiro, D. J. Moojen, N. Kobayashi, W. J. Dhert, T.W. Bauer. Clinical Orthopedics and Related Research. 469 (4), 1127 (2011). Crossref

4. R.Z. Valiev, A.P. Zhilyaev, T.G. Langdon. Bulk Nanostructured Materials: Fundamentals and Applications. Hoboken, New Jersey, John Wiley \& Sons (2014) 440 p. Crossref

5. R. Z. Valiev. Russian Nanotechnology. 1 (1-2), 208 (2006). (in Russian) [Р.3. Валиев. Российские Нанотехнологии. 1 (1-2), 208 (2006).]

6. G.V. Klevtsov, E.V. Bobruk, I.P. Semenova, N.A. Klevtsova, R.Z. Valiev. Strength and fracture mechanisms of bulk nanostructured metallic materials. Ufa, UGATU (2016) 240 p. (in Russian) [Г.В. Клевцов, Е.В. Бобрук, И.П. Семенова, Н.А. Клевцова, Р.3. Валиев. Прочность и механизмы разрушения объемных наноструктурированных металлических материалов. Уфа, УГАТУ (2016) 240 с.]

7. I. A. Ovid'ko, R.Z. Valiev, Y.T. Zhu. Progress in Materials Science. 94, 462 (2018). Crossref

8. R.K. Islamgaliev, M.A. Nikitina, A.V. Ganeev, V.D. Sitdikov. Materials Science and Engineering A. 744, 163 (2019). Crossref

9. J. Stráský, M. Janeček, I. Semenova, J. Čížek, K. Bartha, P. Harcuba, V.V. Polyakova, S. Gatina. Titanium in Medical and Dental Applications. 2018, 455 (2018). Crossref

10. D. V. Gunderov, A. V. Polyakov, I. P. Semenova, G. I. Raab, A.A. Churakova, E.I. Gimaltdinova, I. Sabirov, J. Segurado, V. D. Sitdikov, I. V. Alexandrov, N. A. Enikeev, R.Z. Valiev. Materials Science and Engineering a-Structural Materials Properties Microstructure and Processing. 562, 128 (2013). Crossref

11. I.P. Semenova, A. V. Polyakov, G.I. Raab, T.C. Lowe, R. Z. Valiev. Journal of Materials Science. 47, 7777 (2012). Crossref

12. V.V. Polyakova, I.P. Semenova, A.V. Polyakov, D. K. Magomedova, Y. Huang, T. G. Langdon. Materials Letters. 190, 256 (2017). Crossref

13. A. V. Polyakov, I.P. Semenova, E. Ivanov, R. Z. Valiev. Materials Science and Engineering. 461, 012077 (2018). Crossref

14. I.P. Semenova, A.V. Polyakov, V.V. Polyakova, Y.F. Grishina, Y. Huang, R.Z. Valiev, T.G. Langdon. Materials Science and Engineering: A. 696, 166 (2017). Crossref

15. R.Z. Valiev, E.V. Parfenov, L.V. Parfenova. Materials Transactions. 60 (7), 356 (2019). $\underline{\text { Crossref }}$

16. L. L. Meisner, M.V. Kotenko, A.B. Mamytova, P. V. Zaritsky, V.T. Egorov. Siberian Medical Journal. 8, 13 (2009). (in Russian) [Л. Л. Мейснер, М.В.Котенко, А.Б. Мамытова, П.В. Зарицкий, В.Т. Егоров. Сибирский медицинский журнал. 8, 13 (2009).] 
17. S. N. Meisner, M. V. Kotenko, V.A. Kopysova, A.I. Yaremenko, I.K. Ratkin. Zabaikalsky Medical Bulletin. 1, 59 (2016). (in Russian) [С.Н. Мейснер, М. В. Котенко, В.А. Копысова, А.И. Яременко, И.К. Раткин. Забайкальский медицинский вестник. 1, 59 (2016).]

18. A.B. Imanaliev, A.A. Imanaliev, A.S. Ayatov. Traumatology and orthopedics. 3-4, 82 (2014). (in Russian) [А.Б. Иманалиев, А.А. Иманалиев, А.С. Аятов. Травматология және ортопедия. 3-4, 82 (2014).]
19. A. V. Bondarenko, E. A. Raspopova, V.A. Peleganchuk. Bulletin of Traumatology and Orthopedics n. a. N. N. Priorov. 2, 41 (2004). (in Russian) [Бондаренко, А. В., Распопова Е.А., Пелеганчук В.А. Вестник травматологии и ортопедии им. Н.Н. Приорова. 2, 41 (2004).] Crossref

20. V.S. Zolotorevskiy. Mechanical properties of metals. Moscow, MISIS (1998) 400 p. (in Russian) [B.С. Золоторевский. Механические свойства металлов. Москва, МИСИС (1998) 400 с.] 